\title{
EFFECT OF IDOL IMMERSION ON WATER QUALITY OF CHANDRABHAGA RIVER IN NAGPUR
}

\author{
A. M. Watkar and M. P. Barbate \\ Department of Zoology, Bhalerao Science College, \\ Saoner, Dist. Nagpur, Maharashtra, INDIA \\ amitawatkar2@gmail.com
}

\begin{abstract}
:
India is the country of rich cultural heritage and festivals. Peoples here celebrate festivals with great enthusiasm. Among all the Indian festivals 'Ganesh utsav' and 'Durga puja' is celebrated by every community. These festivals end by idol immersion in water. These idols are made up of degradable and non-degradable components and paints containing heavy metals due to that immersion activity deteriorates water quality. The present study has been made to analyze the physicochemical parameters of the Chandrabhaga river after idol immersion for analyzing the various physicochemical parameters such as Temperature, $\mathrm{pH}$, TDS, DO, Phosphate, Nitrate, BOD, COD, Oil \& Grease, etc. The work highlights the condition of this river water after idol immersion with respect to the parameters mentioned above.

Keywords: Idol, immersion, Chandrabhaga river, physic-chemical.
\end{abstract}

\section{Introduction:}

India is a multi-cultural country of myriad festivals. Some of these festivals involve 'idol immersion' in water as celebrations finale. Ganesh festival is one of the prominent festivals celebrated by all communities irrespective of their cast creed and religion. Beautifully carved and decorated idols are drowned into water bodies like rivers, ponds and lakes with prayers for success, happiness and peace. Two major festivals in India that involve idol immersion are 'Ganesh Chaturthi', dedicated to Lord Ganesha and 'Durga Puja' dedicated to Goddess Durga.

However, amidst the celebrations, people tend to forget the ill-effects of the practice. The most serious impact of idol immersion is on the environment. It disturbs the ecological balance by polluting water and adversely affecting the flora and fauna. The requirement of water is in all lives, i.e. from micro-organisms to man, is a serious problem today because all water resources have been reached to a point of crisis due to unplanned urbanization and industrialization, Singh et. al. (2002). According to Bajpai et al. (2002), the idols of deities are made of non-biodegradable materials such as plastic, cement and plaster of paris and are painted with toxic dyes that contain harmful and toxic chemicals. When they come in contact with water, it becomes poison. All forms of life depend upon water and it provides sustenance to plants, animals, aquatic organisms and to meet the human need like agriculture and industries, Prasad and Gaur (1992). Water gets polluted by dumping domestic, industrial and hospital waste and domestic activities like washing, bathing and religious rituals, Shukla (2004) and Gupta et al. (2011). Thousands of
Ganesh and Durga idols of various sizes reaching heights up to 20 to 40 feet are immersed every year in different water bodies, Reddy and Kumar (2001).

\section{Material and Methods:}

For this study, site has been selected of Chnadrabhaga river near Kalmeshwar, Nagpur Dist. Samples were collected and preserved from the river as per standard methods. Samples were collected during idol immersion successive three days of immersion activities from the site. The samples were subjected to physic-chemical analysis including $\mathrm{pH}$, temperature, dissolved oxygen, total calcium, total hardness, total alkalinity, phosphates, nitrates, biological oxygen demand, chemical oxygen demand, oil and grease, following the procedures prescribed by standard methods, Trivedy and Goel (1986) and APHA (2005).

The analysis of physico-chemical parameters of the Chandrabhaga river was conducted in the laboratory of Bhalerao Science College, Saoner. Physical parameters were studied according to Welch (1948) and Lind (1979) and chemical parameters were studied by using APHA.

\section{Result and Discussion:}

pH: $\mathrm{ph}$ was analysed by $\mathrm{pH}$ meter and it is found that values of the river was changed i.e. Hydrogen ion concentration is considered as a important ecological factor, which is a result of addition of organic substances and materials used in preparation of idols. Nearly neutral $\mathrm{pH}$ of water is regulated by carbon dioxide and bicarbonates, Hutchinson (1957). The river water showed well alkaline water through the study period. $\mathrm{pH}$ of river water was found to be 8.2 . 
Temperature: The water temperature is one of the important parameter in river. In the present study, water temperature was found to be 32 . The studies showed the increased temperature of the river speed up the chemical reaction and biological activity that reduces the solubility of gases in water, Murugesan et al. (2004).

T.D.s.: Total dissolved solids include salt and variety of organic substances, which readily dissolve in water and often impart a degree of hardness. The value of total dissolved solids after idol immersion was found to be $316 \mathrm{mg} / \mathrm{lit}$. Total Alkalinity: Total alkalinity of water is mainly due to cations of Calcium, magnesium, Sodium and Potassium. It is also due to combined carbonate or bicarbonate or occasionally hydroxides. According to Waikol and Patil (2009) analysis of water showed the higher alkalinity which was due to idol immersion. Ujjania and Multani (2011) and Mallik et al (2010) also reported the same.

Total Hardness: During idol immersion activity total hardness in river water was found to be $177 \mathrm{mg} / 1$, which was high value. This result was evident by Vyas et al (2006) and Malik et al (2012).

Dissolved Oxygen: Dissolved oxygen is also one of the important factors of water quality, which influences the biota present inside the river water. The idol immersion adversely affects the dissolved oxygen in water body and during this study it was observed low in river water. Decrease in DO was due to the immersion activity and rise in temperature, Malik et al (2010).

Biological Oxygen Demand: Biological oxygen Demand is a direct measure of $\mathrm{O} 2$ requirement and indirect measure of biodegradable organic matter. The increased value of B.O.D. was again due to the idol immersion. Similar findings were observed by Jadhav and Dongare (2009).

Chemical Oxygen Demand: Chemical Oxygen Demand indicates the extent of chemical pollution mainly from chemicals used during idols painting. The C.O.D. values observed maximum during idol immersion. Similar findings were observed by Vyas and Bajpai (2008) and Dhote et al (2001).

Nitrates: In the present study, nitrate values were increased after idol immersion because of organic matter along with idol immersion. Similar findings were shown by Dhote and Dixit (2011).

Phosphates: Phosphate is considered to be the most significant among the nutrients responsible for eutrophication of water bodies, as it is primary initiating factor. Concentration of phosphates recorded after idol immersion was increased. It may be due to deposition of ashes and chemical under religious activities and decomposition of organic matter in the water sediments.

Oil \&Grease: Oil and grease if present in excess amount it interfere with aerobic and anaerobic biological process. It is present in the water can be extracted either, which is immiscible in water and can be separated by a separator funnel. In the present study oil and grease in river water was found to be 0.71 . The values of oil and grease were increased due to oil paints for painting the idols and oil offering by the devotees during worship..

Total Calcium: Values of total calcium in the river water was observed very high due to the immersion activity. The concentration of Calcium increases due to the idol immersion, Reddy et al (2001).

Table 1: Physico-chemical parameters of Chandrabhaga river at Idol Immersion point.

\begin{tabular}{|l|l|l|}
\hline Sr. No. & Parameter & Station 1 \\
\hline 1. & $\mathrm{pH}$ & 8.2 \\
\hline 2. & Temperature $\left({ }^{\circ} \mathrm{c}\right)$ & 32 \\
\hline 3. & T.D.S. $(\mathrm{mg} / 1)$ & 316 \\
\hline 4. & Total Alkalinity $(\mathrm{mg} / 1)$ & 169 \\
\hline 5. & Total Hardness $(\mathrm{mg} / 1)$ & 177 \\
\hline 6. & D. O. $(\mathrm{mg} / 1)$ & 1.1 \\
\hline 7. & B.O.D. $(\mathrm{mg} / 1)$ & 5.8 \\
\hline 8. & C.O.D. & 51.14 \\
\hline 9. & Nitrates $(\mathrm{mg} / 1)$ & 0.018 \\
\hline 10. & Phosphates $(\mathrm{mg} / 1)$ & 0.067 \\
\hline 11. & Oil \& Grease & 0.71 \\
\hline 12. & Total Calcium $(\mathrm{mg} / 1)$ & 134 \\
\hline
\end{tabular}

\section{Conclusion:}

The present study on assessment of idol immersion on water quality of Chandrabhaga river shows that the idol immersion has negative impact on physical and chemical properties of water. Mythologically the water bodies are related religious sentiments but scientifically these are not suitable for human uses. This religious activity cannot stop but awareness among the people and proper ways through which idol immersion practice can be carried out without harming the environment. Some unique and creative methods should be adopted to make eco-friendly idols, naturals colours etc. which can solve this pollution problem up to some extent.

\section{References:}

1. Singh, S.P., Pathak, D. \& Singh, R. Hydrobiological studies of two ponds of Satna (MP), India, Eco. Evn. And Cons., 8(3), 289-292 (2002) 
2. Bajpai, A., Pani, S., Jain, R.K. \& Mishra, S.M., Heavy metal contamination through idol immersion in a tropical lake. Eco: Environment and Conservation Organization 8(2) 157-159 (2002)

3. Prasad, D. and Gaur, H.S. Environmental pollution: Water, Venus Publishing House, New Delhi 294-330 (1992)

4. Shukla, S.S. Effect of public awareness campaign in mitigating impact of religious activities on Bhopal lakes, Abstract in image of water in religion, myths, literature, Switzerland, Global Biodiversity Forum, 17(2) (2004)

5. Gupta, A.K., Mishra, K., Pramod Kumar, Singh, C.S. \& Srivastava, S. Impact of religious activities on the water characteristics of prominent ponds at Varanasi (UP) India. Plant Archives 11(1) 297-300 (2011)

6. Reddy, V.M. and Kumar, V.A. Effect of Ganesh idol immersion on some water quality parameter of Hussain Sagar, Current Science 1412 (2001)

7. Trivedy, P.K. and Goel, R.K. Chemical and Biological methods water pollution studies. Environmental publication Karad India (1986)

8. APHA, Standard methods for examination of water and waste water. American Public Health Association, Washington, D.C., $21^{\text {st }}$ Edition (2005)

9. Welch, P.S. Limnological methods. Blakiston, Philadelphia, $381 \mathrm{p}$ (1948)

10. Lind, O.T. A handbook of Limnological methods, C.V. Mosby, St. Louis, 199pp (1979)

11. Hutchinson, G.E.A treatise on limnology vol. II John Wiley and Sons, New York, 1015 (1957)

12. Murugesan, S., Kumar, D.S., Rajan, S. \&Chandrika, D. Comparative study of ground water resources of east and west regions of Chennai, Tamilnadu, Nature Environment and Pollution Technology 3(4) 495-499 (2004)
13. Waikol, V. and Patil, C.L. Study of water quality and trace metal concenteration of well-water in dahanu region (Thane, India). Pollution Research 28(2) 305-307 (2009)

14. Ujjania, N.C. and Multani, A.A. Impact of Ganesh idol immersion activities on the water quality of Tapi River, Surat (Gujrat) India. Research Journal of Biology 1(1) 11-15 (2011)

15. Malik, G.M., Raval, V.H., Zadafiya, S.K. \& Patel, A.V. Idol immersion and physic-chemical properties of South Gujrat rivers. Current World Environment Journal 5(1) 173-176 (2010)

16. Vyas, A. Mishra, D.D., Bajpai, A., Dixit, S. and Verma, N. Environment Impact of idol immersion Activity Lakes of Bhopal India. Asian Journal of Experimental Sciences 20(2) 289-296 (2006)

17. Malik, G.M., Raval, V.H., Zadafiya, S.K. \& Patel, A.V. Idol immersion and physic-chemical properties of South Gujrat rivers India. Research Journal of Chemical Sciences 2(3) 21-25 (2012)

18. Jadhav, P. and Dongare, M. Evaluation of dissolved oxygen in Ex Situ Ganesh Idol immersion. Nature Environment and Pollution Technology 8(3) 561-564 (2009)

19. Vyas, A. and Bajpai, A. Water quality survey and monitoring study of idol immersion in context of lower lake Bhopal India. In: Proceedings of tall 2007: the $12^{\text {th }}$ World Lake Congress edited by Sen Gupta $M$ and Dalwani R 1818-1823 (2008)

20. Dhote, S., Varghese, B. \& Mishra, S.M. Impact of idol immersion on water quality of twin lakes of Bhopal. Indian Journal of Environment Protection 21 998-1005 (2001)

21. Dhote, $\mathbf{S}$. and Dixit, S. Hydro chemical changes in two eutrophic lakes of Central India after immersion of Durga and Ganesh idol. Research Journal of Chemical Sciences 1(1) 38-45 (2011) 